\title{
UM OLHAR NO PIBID COMO POLÍTICA PÚBLICA EDUCACIONAL NA FORMAÇÃO DOCENTE
}

\author{
A look at PIBID as a public educational policy in teaching training
}

\section{Una mirada en el PIBID como política pública educacional en la formación docente}

Stéfanie Santos Novaes ${ }^{1}$ https://orcid.org/0000-0001-8972-9620 Nereida Maria Santos Mafra de Benedictis ${ }^{2}$ https://orcid.org/0000-0001-9257-3487

\footnotetext{
${ }^{1}$ Graduada em Geografia pela Universidade Estadual do Sudoete da Bahia - UESB, Brasil, email -stefanienovaes@ gmail.com

${ }^{2}$ Professor(a) Adjunto do Departamento de Gografia da Universidade Estadual do Sudoete da Bahia - UESB, Brasil, email nnereidamafrabenedictis@gmail.com
}

\section{Resumo}

O presente artigo tem o objetivo analisar o Programa Institucional de bolsas de Iniciação à Docência (PIBID) subprojeto de Geografia, com o intuito de compreender as contribuições do programa para a formação docente. Buscou-se analisar a relação entre a teoria e a prática e as inovações que o programa proporcionou. Fez-se necessário problematizar a formação docente, buscando compreender o quadro educacional do Brasil, analisando as transformações e o contexto em que se inserem, partindo inicialmente por uma análise das políticas públicas educacionais voltadas para o magistério. Chegando- se a conclusão que o PIBID subprojeto de Geografia contribui para a formação docente, por meio da relação teoria e prática do programa ao manter um contato direto com o ambiente escolar.

Palavras-chave: Formação docente. Programa Institucional de Iniciação à Docência. Teoria e Prática.

\begin{abstract}
The present article has the objective of analyzing the Programa Institucional de bolsas de Iniciação à Docência (PIBID) subproject of Geography, in order to understand the contributions of the program to teacher education. We sought to analyze the relationship between theory and practice and the innovations that the program provided. It was necessary to problematize the teacher training, seeking to understand the educational framework of Brazil, analyzing the transformations and the context in which they are inserted, initially starting with an analysis of educational public
\end{abstract}


policies geared towards teaching. The conclusion is that the PIBID subproject of Geography contributes to the teacher formation, through the relation theory and practice of the program while maintaining a direct contact with the school environment

Keywords: Teacher Formation. Institutional Program of Initiation to Teaching. Teory and practice

\section{Resumen}

El presente artículo tiene el objetivo de analizar el Programa Institucional de becas de Iniciación a la Docencia (PIBID) subproyecto de Geografía, con el fin de comprender las contribuciones del programa para la formación docente. Se buscó analizar la relación entre la teoría y la práctica y las innovaciones que el programa proporcionó. Se hizo necesario problematizar la formación docente, buscando comprender el cuadro educativo de Brasil, analizando las transformaciones y el contexto en que se insertan, partiendo inicialmente por un análisis de las políticas públicas educativas dirigidas al magisterio. Al llegar a la conclusión de que el PIBID subproyecto de Geografía contribuye a la formación docente, a través de la relación teoría y práctica del programa al mantener un contacto directo con el ambiente escolar.

Palabras clave: Formación Docente. Programa Institucional de Iniciación a la Docencia. Teoría y Práctica

\section{Introdução}

O PIBID surgiu por meio da Coordenação de Aperfeiçoamento de Pessoal de Nível Superior (CAPES) no ano de 2007. Segundo a CAPES (2013, p.27) “Ao ser lançado, em 2007, a prioridade de atendimento do Pibid eram as áreas de Física, Química, Biologia e Matemática para o ensino médio" E no ano de 2009 se expandiu para as demais licenciaturas. Surgiu como uma política pública voltada para a formação inicial de professores, como um estímulo a valorização docente. Segundo o MEC o programa tem como objetivo articular a educação superior com a educação básica, possibilitando que o licenciando passa fazer parte do ambiente escolar como um todo, não apenas a sala de aula, mas inserindo-o no ambiente escolar da educação básica. Esse processo contribui para a formação acadêmica e humana aos estudantes das licenciaturas, pois permite a relação ensino-aprendizagem por meio do desenvolvimento das práticas pedagógicas.

O interesse por essa temática justifica-se pela necessidade em compreender a proposta de tal programa e qual a sua importância para a formação docente, tendo como recorte analítico o curso de Licenciatura em Geografia da Universidade Estadual do Sudoeste da 
Bahia, campus de Vitória da Conquista-BA. Formação docente e das leis que a regem em âmbito nacional, realizando uma breve análise sobre o histórico da trajetória da formação de professores no Brasil e suas transformações ao longo dos anos.

As leituras utilizadas como suporte para a fundamentação teórica, com o intuito de apreender acerca do objeto da pesquisa, será utilizado a Lei de Diretrizes e Bases da Educação Nacional (LDB/1996), Pimenta(1999), Mello(2000) Marques (2007) Saviani (2005), Plano Nacional da Educação (PNE) Dicionário de filosofia (2007) Dicionário de pedagogia

\section{Um olhar nas políticas públicas para a formação docente}

As políticas públicas são um conjunto de programas e de ações dos governos, federal, estadual e municipal, que são desenvolvidas com o intuito de promover o bem-estar da sociedade. Assim, "Segue o mesmo veio: política pública é a soma das atividades dos governos, que agem diretamente ou através de delegação, e que influenciam a vida dos cidadãos”. Peters (1986, apud SOUZA, 2006, p.5)

Assim como todas as profissões surgem em um determinado contexto, a profissão docente emerge se transforma e se adequa de acordo as mudanças que ocorrem na sociedade constantemente, necessitando a adequação ao cotidiano dos alunos, como forma de acompanhar esses processos. "A profissão de professor, como as demais, emerge em dado contexto e momento históricos, como resposta a necessidades que estão postas pelas sociedades, adquirindo estatuto de legalidade" (PIMENTA, 1999, p.18)

Ao se discutir a formação docente, outras questões referentes a docência emergem, questões essas relacionadas aos aspectos de valorização financeira, dificuldades encontradas dentro da profissão e dificuldades do professor possuir um domínio de classe perante a turmas de alunos agitados e turbulentos e de escolas que não propiciam condições necessárias, assim como afirma Pimenta:

Também sabem sobre o ser professor por meio da experiencia socialmente acumulada, as mudanças históricas da profissão, o exercício profissional em diferentes escolas, a não valorização social e financeira dos professores, as dificuldades de estar diante de turmas de crianças e jovens turbulentos, em escolas precárias. (PIMENTA, 1999, p.20)

A sociedade passa por diversas transformações ao longo dos anos em diversos aspectos, atingindo de forma direta a educação e exigindo uma adequação dos processos 
educacionais frente a essas mudanças, para que seja possível atender as necessidades dos alunos.

Em resposta a essas expectativas, desde a década de 80 os sistemas de ensino público e privado vêm passando por processos de reforma educacional, em âmbito estadual, local ou mesmo nas unidades escolares. Algumas dessas iniciativas de reforma são mais abrangentes e atingem todos os componentes do processo educativo; outras dirigem-se a apenas alguns deles (MELLO, 2000, p.98)

As transformações que ocorrem em um determinado contexto, requerem também uma transformação nos sistemas de ensino, com o objetivo de acompanhar e se adequar, pois geram expectativas relacionadas a ampliação da educação na sociedade.

Para a abordagem da prática da docência é necessário que se faça uma análise das leis que darão suporte a formação docente, contribuindo para um entendimento mais claro da profissão, partindo para a análise da Lei de Diretrizes e Bases da Educação(LDB) foi aprovada em dezembro do ano de 1996, também é conhecida como lei Darcy Ribeiro, como uma homenagem ao político, educador brasileiro e formulador desta lei. A Lei possui 92 artigos em sua composição, que abordam questões relacionadas a educação brasileira, da educação infantil até o ensino superior, servindo para reafirmar os direitos que já são dispostos na constituição federal. É importante enfatizar que apenas a LDB sozinha não garante a efetivação dos direitos, porém serve como suporte para novas legislações ao longo desses 22 anos novas emendas constitucionais e leis modificaram o quadro da educação brasileira, inclusive modificações na própria LDB.

Partindo para uma abordagem mais específica, relacionada à formação docente, a LDB norteia as modalidades de ensino, e em seu Artigo 43, Capítulo IV aponta sobre a finalidade da educação superior, dentre elas:

I - estimular a criação cultural e o desenvolvimento do espírito científico e do pensamento reflexivo; II - formar diplomados nas diferentes áreas de conhecimento, aptos para a inserção em setores profissionais e para a participação no desenvolvimento da sociedade brasileira, e colaborar na sua formação contínua; III - incentivar o trabalho de pesquisa e investigação científica, visando o desenvolvimento da ciência e da tecnologia e da criação e difusão da cultura, e, desse modo, desenvolver o entendimento do homem e do meio em que vive (BRASIL, LDB, 1996, p.44).

É possível verificar nos objetivos que o ensino superior deve cumprir, para que os graduandos possam ter uma formação efetiva, por meio do incentivo ao pensamento reflexivo, 
estando em consonância com as propostas do curso, em que o aluno deva se reconhecer enquanto participante da sociedade.

Com relação a formação docente, de forma continuada, a LDB deixa explicito em seu Artigo 67, sobre a valorização dos profissionais da educação, assegurando-lhes nos termos de estatutos e de planos de carreira do magistério público:

I - ingresso exclusivamente por concurso público de provas e títulos; II aperfeiçoamento profissional continuado, inclusive com licenciamento periódico remunerado para esse fim; III - piso salarial profissional; IV progressão funcional baseada na titulação ou habilitação, e na avaliação do desempenho; V - período reservado a estudos, planejamento e avaliação, incluído na carga de trabalho; VI - condições adequadas de trabalho(BRASIL, 1996 p.44).

Durante o artigo 67 são assegurados os direitos relativos ao ingresso por meio do concurso público, o piso salarial, um período que deva ser destinado aos estudos realizados pelo professor, o planejamento do material didático e a avaliação, estando inclusos na carga horaria do professor, outro aspecto importante são as condições necessárias para a realização do trabalho docente.

Ainda sobre a formação docente, a LBD traz o artigo 62 que garante elevar a formação dos docentes em nível superior, assim como está disposto no artigo:

A formação de docentes para atuar na educação básica far-se-á em nível superior, em curso de licenciatura plena, admitida, como formação mínima para o exercício do magistério na educação infantil e nos cinco primeiros anos do ensino fundamental, a oferecida em nível médio, na modalidade normal (BRASIL, 1996 p. única )

O referente artigo prevê que a formação docente que atuarão na educação básica seja em nível superior, no curso de licenciatura plena nas universidades, elevando a formação mínima que se exige para os docentes que irão atuar no ensino fundamental, já a formação no nível médio é admitida para professores que atuem na educação infantil, sendo um artigo fundamental para a valorização do magistério, contribuindo para o aumento da qualidade da educação básica.

Entretanto, Saviani faz uma análise acerca do artigo 62 e sua falha,

A referida falha consiste em que, no artigo 62, fixa-se a regra de que a formação de docentes para a educação básica será feita em nível superior. Mas, no mesmo artigo, se introduz a exceção, admitindo-se como formação mínima o nível médio, sem estabelecimento de prazo. (SAVIANI, 2005 p.22) 
No Artigo citado pelo autor é enfatizado sobre a necessidade da formação docente em instituições de ensino superior para atuarem na educação básica. Contudo, contradiz quando dispõe sobre a exceção da regra anteriormente posta, admitindo a formação mínima no nível médio para a atuação docente.

E em seu $\S 5^{\circ}$ prevê sobre o incentivo a formação docente por meio do Programa Institucional de Bolsas de Iniciação à Docência:

A União, o Distrito Federal, os Estados e os Municípios incentivarão a formação de profissionais do magistério para atuar na educação básica pública mediante programa institucional de bolsa de iniciação à docência a estudantes matriculados em cursos de licenciatura, de graduação plena, nas instituições de educação superior. (BRASIL, 1996, p.única)

Ação em conjunto entre a união, o distrito federal, estados e municípios com o intuito de incentivar a formação docente, para atuarem na educação básica, este incentivo sendo realizado por meio do programa institucional de bolsa de iniciação à docência destinados aos graduandos

Entretanto, surge outro questionamento relacionado ao cumprimento do que está disposto na LDB, tais artigos são capazes de suprir as necessidades e dificuldades encontradas no cenário educacional? Saviani traz algumas considerações nessa perspectiva

Podemos, pois, concluir que as esperanças depositadas na nova Lei de Diretrizes e Bases da educação Nacional, consubstanciadas na Lei n.9.394 de 20 de dezembro de 1996, no sentido de que ela viesse a enfrentar com êxito o problema da formação de professores, resultaram frustradas. Com efeito, abortado o dispositivo legal que elevaria o preparo de todos os professores ao nível superior; e considerando-se que a inovação dos institutos superiores de educação representa um forte risco de nivelamento por baixo. [...] ( SAVIANI, 2005, p.25)

O autor aborda sobre a ambiguidade e as falhas formais contidas na Lei, e que são depositadas esperanças na mesma, quando se espera que ela enfrente os problemas relacionados com a formação docente. Saviani afirma que busca-se elevar o preparo dos professores para o nível superior, entretanto, para que isso ocorra, as inovações dos institutos superior deveriam seguir o mesmo ritmo, mas não é essa a realidade, assim seria considerado um nivelamento por baixo.

\section{O PIBID como política pública educacional na formação docente}


Compreende-se o Programa Institucional de Bolsas de Iniciação à Docência (PIBID), como uma política pública voltada para a formação inicial de professores, com o intuito de estimular a formação docente. A característica primordial do programa fundamenta-se na articulação entre a teoria e a prática no processo ensino aprendizagem, com a proposta de envolver os graduandos no ambiente escolar.

Existe uma diferença basilar entre as concepções de educação e ensino, desta forma, foi utilizado o dicionário de sociologia e filosofia e o dicionário de pedagogia, com o objetivo de melhorar a compreensão, trazendo a diferenciação entre as concepções e realizando uma analise sobre a utilização dos mesmos nos documentos referentes a formação docente e nas legislações federal e estadual. Conforme ABBAGNANO, a educação corresponde:

Em geral, designa-se com esse termo a transmissão e o aprendizado das técnicas culturais, que são as técnicas de uso, produção e comportamento, mediante as quais um grupo de homens é capaz de satisfazer suas necessidades, proteger-se contra a hostilidade do ambiente físico e biológico e trabalhar em conjunto, de modo mais ou menos ordenado e pacífico. Como o conjunto dessas técnicas se chama cultura (v. CULTURA, 2), uma sociedade humana não pode sobreviver se sua cultura não é transmitida de geração para geração; as modalidades ou formas de realizar ou garantir essa transmissão chamam-se educação(ABBAGNANO 2007 p. 305)

Assim, segundo o autor citado a educação é definida como a transmissão dos conhecimentos relacionados com a cultura e com o conjunto de técnicas que o ser humano desenvolve com o intuito de satisfazer suas necessidades, técnicas essas para se protegerem no ambiente em que vivem, e de trabalharem em conjunto, a educação se caracteriza por perpetuar ao logo dos anos e das gerações aquilo que foi alcançado no processo de transformações sociais, o conjunto dessas técnicas são denominadas de cultura e por meio da educação a cultura sobrevive e é transmitida.

No dicionário de pedagogia traz a concepção do ensino:

Processo pelo qual o professor transmite ao aluno o legado cultural em qualquer ramo do saber. $\mathrm{O}$ ensino anda associado à transmissão do saber já constituído. As pedagogias construtivistas consideram que o acto de ensinar deve subordinar-se à aprendizagem e está ao desenvolvimento. O professor passa a desempenhar novos papéis: facilitador da aprendizagem, dinamizador de situações problemáticas e orientador de projectos. (MARQUES, 2011, p.42)

O ensino será concebido como um conhecimento previamente constituído, sendo transmitido pelo professor, considerando que este ato deve estar relacionado ao 
desenvolvimento, o professor realizando a função de orientador e facilitador da aprendizagem desse aluno dentro do processo de ensino aprendizagem.

A educação é considerada como um processo de aprendizagem do indivíduo e quando este processo ocorre nas escolas, é considerado como ensino, sendo responsabilidade das instituições de ensino, que será trabalhado com base no processo de formação escolar, por meio das trocas de conhecimentos entre alunos e professores e utilização de métodos.

Na LDB trata-se da educação infantil e educação superior e ensino fundamental e ensino médio, com suas finalidades e objetivos referentes a cada um, compreendendo que em âmbito constitucional o termo adequado ao artigo 206 é educação por ser mais amplo e abrangente.

O Plano Nacional de Educação (PNE) foi aprovado em 26 de junho de 2014, é um plano decenal, ou seja com validade de 10 anos, por meio desse plano são estabelecidas as diretrizes estratégias e metas com o intuito de reger as ações na área da educação, para isso é necessário que os Estados e Municípios participem do planejamentos para alcançar os objetivos que foram previstos, levando em consideração os aspectos da situação local. Deixando claro que, deve-se:

Garantir, em regime de colaboração entre a União, os Estados, o Distrito Federal e os Municípios, no prazo de 1 (um) ano de vigência deste PNE, política nacional de formação dos profissionais da educação de que tratam os incisos I, II e III do caput do art. 61 da Lei no 9.394, de 20 de dezembro de 1996, assegurado que todos os professores e as professoras da educação básica possuam formação específica de nível superior, obtida em curso de licenciatura na área de conhecimento em que atuam. (PNE, 2014)

Com relação a formação docente o PNE em sua meta 15, que é necessário que se tenha a colaboração entre a União, os Estados e o Distrito Federal e Municípios, com o intuito de assegurar que os docentes possuam formação de nível superior na área em que atuam.

Desse modo, a meta de número 15, relacionada a formação docente possui 13 estratégias com a finalidade de buscar a sua efetivação, sendo a primeira estratégia com o objetivo de:

[...] atuar, conjuntamente, com base em plano estratégico que apresente diagnóstico das necessidades de formação de profissionais da educação e da capacidade de atendimento, por parte de instituições públicas e comunitárias de educação superior existentes nos Estados, Distrito Federal e Municípios, e defina obrigações recíprocas entre os partícipes; (PNE, 2014). 
É evidente a necessidade de uma ação em conjunto com o intuito de promover uma educação de qualidade, possuindo como base um plano que identifique quais são as necessidades relacionadas a formação dos profissionais da educação, definindo as obrigações aos que participam.

[...] Entende, também que a formação é, na verdade, autoformação, uma vez que os professores reelaboram os saberes iniciais em confronto com suas experiencias práticas, cotidianamente vivenciadas nos contextos escolares. É nesse confronto e num processo coletivo de troca de experiencias e práticas que os professores vão constituindo seus saberes como praticum, ou seja, aquele que constantemente reflete na e sobre a prática. (PIMENTA, 1999, p.29).

Assim, a formação docente é a junção dos seus saberes iniciais com suas experiencias práticas do cotidiano escolar, juntamente com a troca de experiencias entre os professores que os saberes vão sendo construídos coletivamente, se refletindo posteriormente na sua prática. Como aponta Tardiff (2002, p. 68) "O desenvolvimento do saber profissional é associado tanto às suas fontes e lugares de aquisição quanto aos seus momento e fases de construção".

Ser professor é estar integrado ao ambiente escolar, interagindo com os demais colegas. Como afirma Tardiff (2002, p.70) “A carreira é também um processo de socialização, isto é, um processo de marcação e de incorporação dos indivíduos às práticas e rotinas institucionalizadas das equipes de trabalho" Por meio dessa interação é possível fazer uma análise da sua prática, aperfeiçoar e trocar experiências. Essa integração é encontrada no programa, por meio da realização das monitorias didáticas, do compartilhamento das experiências com os demais colegas durante as socializações, importante durante a graduação, pois é possível se familiarizar com o ambiente profissional, antes mesmo do estágio supervisionado.

Mello (2000) enfatiza a importância da prática na formação docente do licenciando, como uma oportunidade de estar em contato com o cotidiano dos alunos. Tal aspecto pode ser encontrado nas vivências do PIBID.

A prática deverá estar presente desde o primeiro dia de aula do curso superior de formação docente, por meio da presença orientada em escolas de educação infantil e ensinos fundamental e médio ou de forma mediada pela utilização de vídeos, estudos de casos e depoimentos ou qualquer outro recurso didático que permita a reconstrução ou simulação de situações reais. (MELLO, 2000 p.104).

Segundo o autor a prática é um aspecto fundamental, pois o graduando tem a oportunidade de levar para a sala de aula o conteúdo e articular com as práticas docentes, o 
que foi e está sendo apreendido durante a graduação. A relação teoria e prática se estabelece da seguinte forma "Para os estudantes de Geografia, participar desse projeto e conhecer o espaço escolar motiva-os a acreditar que é possível uma formação docente consolidada que relaciona a teoria e a prática.” (TRINDADE et.al, p.52, 2017)

\section{Considerações finais}

Após essa abordagem da LDB, do PNE e por meio da contribuição de autores que abordam sobre a formação, fica explicito a necessidade e um esforço de uma ação conjunta, com a participação e integração de todos dentro desse processo formativo, ficando mais claro de se compreender, levando em consideração o contexto histórico e as transformações que ocorrem durante esse período. As leis que regem a educação evidenciam os objetivos, partindo do pressuposto da solidariedade, liberdade, igualdade de acesso e respeito. Compreendemos a profissão docente, inserida dentro dos processos de transformação da sociedade, necessitando que o graduando acompanhe essas mudanças, e por meio da análise da legislação foi possível verificar os processos que fizeram parte da formação docente.

O professor começa a conhecer e a refletir sobre as políticas públicas voltadas ao ensino, como uma forma de se reconhecer dentro da profissão, contribuinte para a formação social, pois além de ser transmissor de conhecimentos, o docente auxilia na formação humana dos alunos, cooperando no desenvolvimento do discente, dentro do processos ensino/aprendizagem.

A educação formadora consiste em transmitir os conhecimentos, atendendo as necessidades dos alunos, levando-os a refletir sobre a interdependência entre os seres humanos, o meio ambiente, com o objetivo de formar cidadãos conscientes. Essa questão é, portanto, um grande desafio para a formação docente.

\section{Referências}

ABBAGNANO, N. Dicionário de filosofia. São Paulo: Martins Fontes, 2007. ALMEIDA, J.L.V.; OLIVEIRA, E.M.; ARNONI, M.E.B.. (Orgs.) Mediação dialética na educação escolar: teoria. e prática. São Paulo: Edições Loyola, 2007. ẢRISTÓTELES. Política. São Paulo, SP: Martin Claret,. 2007.

BRASIL. Ministério da Educação e do Desporto. Plano Nacional de Educação / Ministério da Educação e do Desporto. - Brasília: Instituto Nacional de Estudos e Pesquisas Educacionais, 1998.

BRASIL. Lei $n^{\circ}$ 9.394. de 20 de dezembro de 1996. Lei de diretrizes e bases da educação.

Disponível em < http://www.planalto.gov.br/ccivil acesso em 20 jul. de 2018.

. Capes. Coordenação de Aperfeiçoamento de Pessoal de Nível Superior. Disponível em acesso em: 02 de julh. 2019 
MARQUES, Ramiro. Dicionário Breve de Pedagogia. 2ª ed .2011 Disponível em: https://pedagogiaaopedaletra.com/wp- content/uploads/2011/10/Dicionario acesso em: 05 set. 2018

MELLO, Guiomar Namo de. Formação inicial de professores para a educação básica: uma (re)visão radical. São Paulo Perspec., São Paulo, v. 14, n. 1, p. 98-110, Mar. 2000 . Disponível em <http://www.scielo.br/scielo.php?script=sci$88392000000100012 \& \operatorname{lng}=$ en\&nrm=iso>. Acesso em 20 jun. 2018.

PIMENTA, Selma Garrido. Formação de professores: identidade e saberes da docência. In: PIMENTA, Selma Garrido. (Org). Saberes pedagógicos e atividade docente. São Paulo: Cortez Editora, 1999. (p. 15 a 34)

SAVIANI, Dermeval, História da formação docente no Brasil: três momentos decisivos. Santa Maria, v. 30-n. 02, p. 11-26, 2005 Disponivel em <http:// www.ufsm.br/ce/revista> acesso em: 05 de agos. 2018

TARDIF, M. Saberes docentes e formação profissional. Petrópolis, RJ: Vozes, 2002.

TRINDADE, et al.A importância da pesquisa etnográfica na formação docente: Conhecendo o espaço escolar e os alunos do CEAP por meio do PIBID/UESB. In: SAMPAIO, Andrecksa Viana Oliveira et al. (Org.). Geografia e História: Reflexões Sobre a Escola Básica. 1. ed. Vitória da Conquista: 